\title{
A uracil auxotroph Toxoplasma gondii exerting immunomodulation to inhibit breast cancer growth and metastasis
}

\author{
Li-Qing Xu, Li-Jie Yao, Dan Jiang, Li-Juan Zhou, Min Chen, Wen-Zhong Liao, Wei-Hao Zou and Hong-Juan Peng ${ }^{*}$
}

\begin{abstract}
Background: Breast cancer is the most common cause of cancer-related death among women, and prognosis is especially poor for patients with triple-negative breast cancer (TNBC); therefore, there is an urgent need for new effective therapies. Recent studies have demonstrated that the uracil auxotroph Toxoplasma gondii vaccine displays anti-tumor effects. Here, we examined the immunotherapy effects of an attenuated uracil auxotroph strain of T. gondii against 4T1 murine breast cancer.

Methods: We constructed a uracil auxotroph T. gondii RH strain via orotidine 5'-monophosphate decarboxylase gene deletion (RH- $\triangle$ ompdc) with CRISPR/Cas9 technology. The strain's virulence in the T. gondii-infected mice was determined in vitro and in vivo by parasite replication assay, plaque assay, parasite burden detection in mice peritoneal fluids and survival analysis. The immunomodulation ability of the strain was evaluated by cytokine detection. Its anti-tumor effect was evaluated after its in situ inoculation into 4T1 tumors in a mouse model; the tumor volume was measured, and the 4T1 lung metastasis was detected by hematoxylin and eosin and Ki67 antibody staining, and the cytokine levels were measured by an enzyme-linked immunosorbent assay.
\end{abstract}

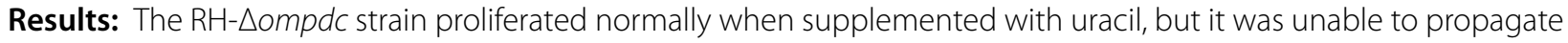
without the addition of uracil and in vivo, which suggested that it was avirulent to the hosts. This mutant showed vaccine characteristics that could induce intense immune responses both in vitro and in vivo by significantly boosting the expression of inflammatory cytokines. Inoculation of RH- $\triangle$ ompdc in situ into the 4T1 tumor inhibited tumor growth, reduced lung metastasis, promoted the survival of the tumor-bearing mice and increased the secretion of Th1 cytokines, including interleukin-12 (IL-12) and interferon- $\gamma$ (INF- $\delta$ ), in both the serum and tumor microenvironment (TME).

Conclusion: Inoculation of the uracil auxotroph $\mathrm{RH}-\triangle o m p d c$ directly into the $4 \mathrm{~T} 1$ tumor stimulated anti-infection and anti-tumor immunity in mice, and resulted in inhibition of tumor growth and metastasis, promotion of the survival of the tumor-bearing mice and increased secretion of IL-12 and IFN- $\gamma$ in both the serum and TME. Our findings suggest that the immunomodulation caused by RH- $\triangle$ ompdc could be a potential anti-tumor strategy.

Keywords: Toxoplasma gondii, Uracil auxotroph, In situ inoculation, Breast cancer, Immunomodulation

*Correspondence: floriapeng@hotmail.com

Department of Pathogen Biology, Guangdong Provincial Key Laboratory of Tropical Disease Research, School of Public Health, Southern Medical University, Guangzhou, Guangdong 510515, People's Republic of China

\section{Background}

Breast cancer is the most common malignancy and the most frequent cause of cancer-related death in women worldwide, with a global incidence of $24.2 \%$ and a mortality of $15 \%$ [1]. Triple-negative breast cancer (TNBC) is defined as a breast tumor lacking the expression of 
estrogen receptor (ER), progesterone receptor (PR), and human epidermal growth factor receptor-2 (HER2). Among the subtypes of breast cancer, TNBC is the most aggressive form of breast cancer, with the highest recurrence rate and poorest prognosis [2-4]. Nowadays, surgery, radiation therapy and chemotherapy are the main therapeutic options for the treatment of breast cancer in clinical practice, and chemotherapy remains the mainstay of TNBC treatment $[2,5,6]$. Although a large number of novel therapies have been evaluated, the effects of clinical treatment on TNBC remain poor [7], which emphasizes the need to explore new therapies for effective TNBC treatment.

The tumor microenvironment (TME) is a complex cellular environment composed of multiple cells that affects tumor progression [8]. In an immunosuppressive TME, various immunosuppressive cells, such as $\mathrm{T}$ regulatory cells (Tregs), myeloid-derived suppressor cells (MDSCs), tumor-associated macrophages (TAMs) and type II natural killer T cells (NKTIIs), contribute to immunosuppression through various mechanisms that promote cancer progression [8]. Cancer immunotherapy can reverse an immunosuppressive TME and remodel the immune system to kill tumor cells $[9,10]$. Various immunosuppressive mechanisms are present in the developmental process of mammary glands [11-13], and these may be utilized by breast cancer cells to influence the development and progression of breast cancer according to immune surveillance and immune editing principles [14$16]$. In the early phase, the immune microenvironment mostly exerts anti-tumor effects, inhibiting tumor progression by producing cytokines and activating natural killer (NK), CD4 ${ }^{+}$and $\mathrm{CD}^{+} \mathrm{T}$ cells [2], suggesting that immunotherapy is a promising strategy to treat breast cancer. Some immunotherapy approaches are effective; for example, the immune checkpoint inhibitor pembrolizumab (targeting programmed cell death protein 1 [PD$1]$ ) is clinically efficacious in metastatic TNBC patients with PD- $1^{+}$tumors, with a reported overall response rate of $18.5 \%$ [17]. However, many effective immunotherapy strategies are often associated with serious complications; for instance, paients treated with immune checkpoint inhibitors have many adverse events, such as cardiovascular toxicity, which has a relatively high mortality rate [18]. Therefore, safe and effective therapeutic strategies are urgently needed.

Microorganisms have long been considered potential immunotherapy agents against cancers. In previous studies, many organisms have shown prominent anti-tumor effects in various cancer models. These include Listeria monocytogenes, Salmonella typhimurium and many other programmable bacteria [19-25], the oncolytic virus Talimogene laherparepvec [26], cowpea mosaic virus [27-30], yellow fever vaccine 17D [31] and the artificial attenuated parasite Toxoplasma gondii [32-37], all of which have been reported to be able to inhibit the growth or metastasis of tumors as well as improve prognosis. Genetic manipulation enables the generation of avirulent or attenuated microorganisms that can induce powerful immune responses, making them effective immune-stimulating anti-tumor agents.

Toxoplasma gondii is an obligate intracellular parasite that can induce immune responses defined by the production of interleukin-12 (IL-12) and interferon- $\gamma$ (IFN- $\gamma$ ) [38] that are similar to the host immune responses against breast cancer. An analysis of the changes in tumor-related factors following $T$. gondii infection revealed that this bacterium affects the breast cancer signaling pathway [39], leading us to conjecture whether the progression of breast cancer could be inhibted by infection with a $T$. gondii vaccine. Nonreplicating avirulent uracil auxotroph vaccine strains (such as $\Delta c p s$ and $\Delta o m p d c$ ) have been reported to grow normally in a culture medium supplemented with exogenous uracil, but be unable to replicate in mice [40, 41]. Earlier studies reported that a $\Delta c p s$ vaccine could inhibit the growth of some solid tumors, including mouse Lewis lung carcinoma [33], B16F10 melanoma [34], ID8-Defb29/Vegf-A ovarian cancer [35] and Pan02 pancreatic cancer [36, 37]. A $\Delta c p s$ vaccine was found to be able to reverse the immunosuppression of tumors, increase the production of type 1 helper cell (Th1) cytokines IL-12 and IFN- $\gamma$ and activate tumorrelated $\mathrm{CD}^{+} \mathrm{T}$ cells to recognize and kill tumor cells [32-37]. These results suggest that the avirulent T. gondii strain may be an effective immunotherapeutic agent for TNBC treatment.

In our study, we constructed an avirulent uracil auxotroph RH- $\Delta o m p d c$ strain that could grow normally in mammalian cells when supplemented with uracil, but which was unable to propagate without uracil and in mice. The potential of the avirulent RH- $\Delta o m p d c$ strain as a biotherapy agent in 4T1 tumor treatment was also evaluated.

\section{Methods}

\section{Animal and animal ethics}

BALB/c mice were obtained from the Animal Experimental Center of Southern Medical University. All animal experimental procedures were approved by the Experimental Animal Care and Use Committee of Southern Medical University (permit no. L2019155). 
All mice were housed under standard conditions with unlimited access to food and water.

\section{Cell lines}

Human foreskin fibroblast (HFF), murine RAW264.7 cells and 4T1 cells were purchased from ATCC (American Type Culture Collection, Manassas, VA, USA) and incubated at $37{ }^{\circ} \mathrm{C}$ under $5 \% \mathrm{CO}_{2}$. HFF and RAW264.7 cells were cultured in DMEM (Dulbecco's Modified Eagle Medium; Gibco/Invitrogen, Thermo Fisher Scientific, Waltham, MA, USA), and 4T1 cells were cultured in RPMI-1640 (Roswell Park Memorial Institute-1640; Gibco/Invitrogen) supplemented with $10 \%(\mathrm{v} / \mathrm{v})$ fetal bovine serum (FBS), 100 units $/ \mathrm{ml}$ of penicillin (Thermo Fisher Scientific) and $100 \mu \mathrm{g} / \mathrm{ml}$ of streptomycin (Thermo Fisher Scientific).

\section{Parasite culture}

Toxoplasma gondii tachyzoites were maintained in HFF monolayers cultured in DMEM supplemented with $1 \%$ FBS (v/v). The uracil auxotroph RH- $\Delta o m p d c$ strain was additionally supplied with $0.2 \mathrm{mM}$ uracil (Sigma-Aldrich, St. Louis, MO, USA) [40, 41]. Freshly egressed parasites purified by passage through a 3- $\mu \mathrm{m}$ polycarbonate filter (Whatman plc, GE Healthcare, Chicago, IL, USA) were used in all experiments.

\section{Generation of T. gondii OMPDC gene knockout strain}

The orotidine 5'-monophosphate decarboxylase (OMPDC) gene knockout strain (RH- $\Delta o m p d c)$ was constructed with CRISPR/Cas9 technology based on an reciprocal hemizygous wild-type strain (RH-WT) following a published protocol [42]. Gene-specific CRISPR plasmid and homologous template were co-transfected into RH-WT tachyzoites. The RH- $\Delta o m p d c$ strain was cultured in HFF cells and screened in the medium with $0.2 \mathrm{mM}$ uracil and $3 \mu \mathrm{M}$ pyrimethamine (SigmaAldrich) by limiting dilution. Positive clones were identified by PCR and quantitative reverse transcription PCR (qRT-PCR) using the primers listed in Additional file 2: Table S1.

\section{Parasite replication assay and plaque assay}

Toxoplasma gondii intracellular proliferation was observed using an indirect immunofluorescence assay. HFF cells were grown on coverslips to $100 \%$ confluence and then infected with tachyzoites of the RH-WT or $\mathrm{RH}-\Delta o m p d c$ strain at a multiplicity of infection of 1 . The infected cells were cultured in a medium supplemented with or without $0.2 \mathrm{mM}$ uracil for $24 \mathrm{~h}$, following which the cells were fixed with methanol, incubated with mouse anti-SAG1 monoclonal antibody (Abcam, Oxford, UK) and incubated with an Alexa Fluor 594-conjugated goat anti-mouse IgG (Invitrogen) according to the manufacturer's guidance for visualizing parasites. The number of the parasitophorous vacuoles (PVs) containing 1, 2, 4, 8 or 16 parasites at different replication stages over 100 vacuoles was counted independently from three separate coverslips. The experiment was repeated three times for statistical analysis.

For the plaque assay, HFF monolayers were grown on coverslips in a six-well plate to $100 \%$ confluence, and then infected with 1000 tachyzoites per well of of the RH-WT or RH- $\Delta o m p d c$ strain. These infected cells were cultured with or without $0.2 \mathrm{mM}$ uracil for 6 days, following which the cells were fixed with $4 \%(\mathrm{v} / \mathrm{v})$ paraformaldehyde and stained with $0.1 \%(\mathrm{v} / \mathrm{v})$ crystal violet; then the number and size of the plaques were analyzed [43].

\section{RNA extraction and qRT-PCR}

RAW264.7 cells were infected with RH-WT and $\mathrm{RH}-\Delta o m p d c$ tachyzoites without uracil supplement for $24 \mathrm{~h}$, following which total RNA of the T. gondii tachyzoites and RAW264.7 cells was extracted using a TRIzol reagent (Invitrogen) and reversely transcribed to cDNA with one-step gDNA removal by using TransScript ${ }^{\circledR}$ II All-in-One First-Strand cDNA Synthesis SuperMix (TransGen Biotech, Beijing, China), following the manufacturer's instructions. The transcription levels of IL-12, IL-6, IL-1 $\beta$, inducible nitric oxide synthase (iNOS) and tumor necrosis factor- $\alpha$ (TNF- $\alpha$ ) normalized with glyceraldehyde 3-phosphate dehydrogenase (GAPDH) were examined by qRT-PCR using a Hieff ${ }^{\mathrm{TM}}$ qPCR SYBR $^{\circledR}$ Green Master Mix (Low Rox; Yesen, China). The relative mRNA levels were calculated with the comparative $\Delta \mathrm{Ct}$ method using the formula $2^{-\Delta \Delta C t}$. All qRT-PCR reactions were performed in technical triplicates. The primers are listed in Additional file 2: Table S2.

\section{Evaluation of the virulence and protective efficacy of RH- $\Delta$ ompdc}

For virulence detection, the freshly egressed RH-WT and RH- $\Delta o m p d c$ tachyzoites were purified as mentioned above and resuspended in phosphate-buffered saline (PBS). The 6- to 8-week-old BALB/c mice were infected with 100 tachyzoites of the RH-WT strain or $10^{6}$ or $2 \times 10^{6}$ tachyzoites of the RH- $\Delta o m p d c$ strain by intraperitoneal (i.p.) injection ( 8 mice per group). The survival of mice was observed for 30 days.

For protective efficacy evaluation, the mice were immunized with PBS or with $10^{6}$ or $2 \times 10^{6} \mathrm{RH}-\Delta o m p d c$ tachyzoites per mouse for 30 days (7 mice per group). The mice were then challenged with $100 \mathrm{RH}-\mathrm{WT}$ tachyzoites per mouse, and the mice were observed for 30 days. 
For the determination of the parasite burden in mice peritoneal fluids, the peritoneal fluids were collected from the infected mice at different time points $(12 \mathrm{~h}$, $24 \mathrm{~h}$ and 5 days) after infection. Genomic DNA was extracted using the DNeasy Blood \& Tissue Kit (Qiagen, Hilden, Germany). The parasite burden in the peritoneal fluids was determined by detecting the B1 gene copies with qPCR (for primers, see Additional file 2: Table S1). Quantitative PCR was performed with the Hieff ${ }^{\mathrm{TM}}$ qPCR $\mathrm{SYBR}^{\circledR}$ Green Master Mix (Low Rox) following the manufacturer's instructions. The standard curve for B1 gene copies (indicating the number of $T$. gondii) was generated as previously described [44].

\section{Construction of mouse tumor model and treatment with RH- $\Delta$ ompdc}

The 4T1 cells were harvested, washed twice with RPMI1640 medium and resuspended in PBS at a concentration of $10^{6}$ cells $/ \mathrm{ml}$. The right flank of 5 - to 6 -week-old female $\mathrm{BALB} / \mathrm{c}$ mice was subcutaneously (s.c.) injected with 100 $\mu \mathrm{l}$ of the mixture. Tumors were allowed to grow for 8 days until their sizes reached $30-50 \mathrm{~mm}^{3}$. The tachyzoites of $\mathrm{RH}-\Delta o m p d c$ were harvested and resuspended in PBS to a concentration of $10^{7} \mathrm{ml}^{-1}$. PBS and RH- $\Delta o m p d c$ were slowly intratumorally (i.t.) injected at one site using a 26 $\mathrm{G}$ injection needle with an injection volume of $100 \mu \mathrm{l}$ to the control and experimental group, respectively. The tumor-bearing mice were treated every 7 days for a total of four treatments. The tumor size was measured every 2 days using vernier calipers and calculated following the formula: Volume $(V)=0.52 \times\left(\right.$ length $\times$ width $\left.^{2}\right)[45]$.

\section{Cytokine assay}

The following enzyme-linked immunosorbent (ELISA) kits were used to detect the cytokines based on the manufacturer's recommendations: Mouse IL-12p40 ELISA Kit (EK2183/2) and Mouse IFN- $\gamma$ ELISA Kit (EK280/3) (MultiSciences, Hangzhou, Multisciences (Lianke) Biotech, Co., Ltd., China). Normal mice were infected with RH-WT or RH- $\Delta o m p d c$ tachyzoites, and tumor-bearing mice were treated with PBS or RH- $\Delta o m p d c$ tachyzoites, as described above. Tumors were harvested at 1,8 , and 13 days after the first treatment and then sliced and homogenized at $4{ }^{\circ} \mathrm{C}$; serum from each mouse was collected accordingly. The tumor samples were centrifuged at $5000 \mathrm{~g}$ for $5 \mathrm{~min}$, and serum samples were centrifuged at $1000 \mathrm{~g}$ for $15 \mathrm{~min}$. The supernatants were subsequently used to measure IL-12 and IFN- $\gamma$ levels using the ELISA kits.

\section{Analysis of lung metastasis for 4T1 tumor}

On day 13 after the first treatment, the mice treated with PBS and RH- $\Delta o m p d c(n=3)$ were euthanized, and the lungs were harvested and fixed in $4 \%(\mathrm{v} / \mathrm{v})$ paraformaldehyde for 2 days. The fixed tissues were then sent to the Servicebio Biotechnology Company (Wuhan, China) for paraffin embedding, slicing and subsequent staining of the slices with hematoxylin/eosin $(\mathrm{H} \& \mathrm{E})$. For immunohistochemistry, the slices were stained with the Ki67 antibody followed by the goat anti-rabbit HRP secondary antibody (Servicebio Biotechnology Company). The stained slices were visualized and photographed with a Nikon microscope using a $20 \times 0.75$ NA objective (Nikon Corp., Tokyo, Japan). The number of positive cells per square millimeter was automatically calculated with Image-Pro Plus 6.0 software.

\section{Statistical analysis}

Data were analyzed and charts were generated using GraphPad Prism 6 (GraphPad Software Inc., San Diego, CA, USA) . A two-tailed Student's t-test was used to compare differences between groups. Both one-way and two-way analysis of variance with Tukey's multiple comparisons test were used to compare differences among multiple groups. Survival data were analyzed using the log-rank (Mantel-Cox) test. Statistical significance was defined as $P<0.05$.

\section{Results}

The OMPDC gene was essential to the proliferation and growth of $T$. gondii in vitro

The defective mutants of de novo pyrimidine biosynthesis are uracil auxotrophs, which are nonreplicating and avirulent in mice $[40,41]$. In order to study the therapeutic effects of the nonreplicating $T$. gondii on $4 \mathrm{~T} 1$ mouse breast cancer, we constructed the uracil auxotrophic mutant with CRISPR/Cas9 technology. The construction schematic diagram is shown in Additional file 1: Figure S1a. The PCR and qRT-PCR results demonstrated that the RH- $\Delta o m p d c$ mutant of $T$. gondii was successfully constructed (Additional file 1: Figure S1b, c).

Parasite replication and plaque assays were used to examine the effects of the OMPDC gene on the intracellular proliferation of $T$. gondii. The parasite replication assay showed that at $24 \mathrm{~h}$ post infection, the number of RH-WT tachyzoites per PV was significantly higher than that of the RH- $\Delta o m p d c$ mutant in the absence of uracil. The number of tachyzoites per PV of the RH- $\Delta o m p d c$ mutant supplied with uracil was remarkably higher than that supplied without uracil, although uracil addition not did not affect the proliferation of the RH-WT strain (Fig. 1a-c). These results indicated that the proliferation of the RH- $\Delta o m p d c$ mutant was significantly inhibited in the absence of uracil, and that uracil addition could rescue the reduced proliferation phenotype of the RH- $\Delta o m p d c$ mutant. Plaque assay results showed 


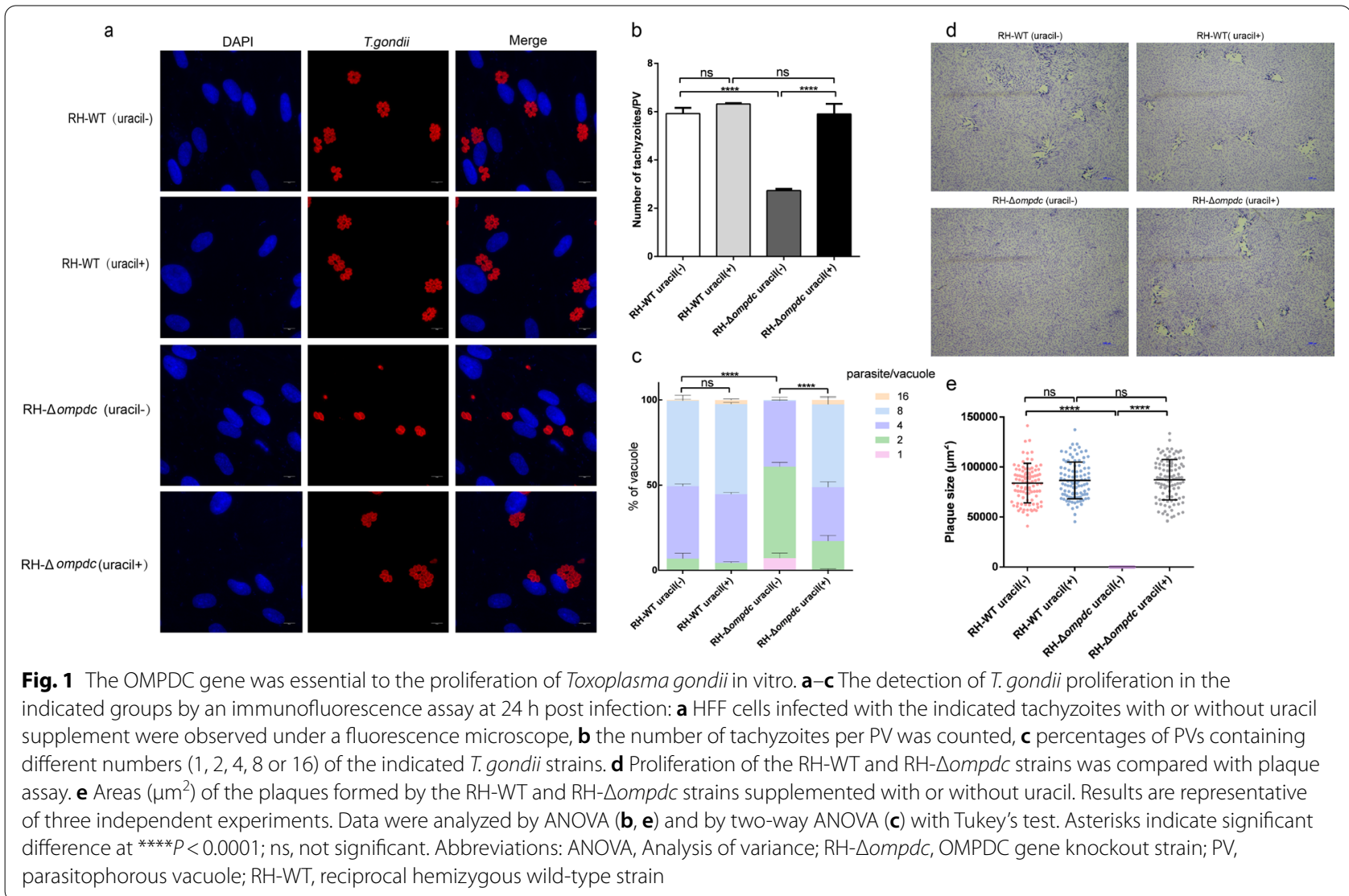

us that the RH- $\Delta o m p d c$ auxotroph could grow normally in the presence of uracil to form plaques, but it failed to do so in the absence of uracil. However, the RH-WT strain was able to grow normally in the culture medium with or without uracil (Fig. 1d, e). These results led us to conclude that the OMPDC gene was essential to the proliferation and growth of $T$. gondii in vitro and that the replication of the RH- $\Delta o m p d c$ mutant could be recovered by uracil supplement.

\section{RH- $\Delta$ ompdc infection significantly increased the transcription levels of proinflammatory cytokines in vitro}

Proinflammatory cytokines, which are predominantly produced by activated immune cells, play central roles in inflammatory diseases. To investigate the ability of the RH- $\Delta o m p d c$ auxotroph to activate macrophages and induce host immune responses, we measured the transcription levels of the cytokines in RAW264.7 cells in the absence of uracil. RAW264.7 cells were infected with RH-WT and RH- $\Delta o m p d c$ tachyzoites without uracil supplement for $24 \mathrm{~h}$, following which the total RNA was extracted and the mRNA levels of cytokines were detected by qRT-PCR. The relative transcription levels of IL-12, IL-6, IL-1 $\beta$, iNOS and TNF- $\alpha$ were significantly increased after T. gondii infection in RAW264.7 cells, regardless of OMPDC gene deletion (Fig. 2). These results indicated that $\mathrm{RH}-\Delta o m p d c$ infection significantly increased the transcription levels of proinflammatory cytokines and may induce strong immune responses in hosts.

\section{Vaccination with the avirulent $\mathrm{RH}-\Delta$ ompdc protected the mice from infection by virulent $\mathrm{RH}$ strain}

To estimate the virulence of the RH- $\Delta o m p d c$ mutant in vivo, $\mathrm{BALB} / \mathrm{c}$ mice were inoculated i.p. with the RH-WT and RH- $\Delta o m p d c$ tachyzoites. Those mice infected with $100 \mathrm{RH}-\mathrm{WT}$ tachyzoites each died within 10 days, while all mice infected with $10^{6}$ or $2 \times 10^{6}$ RH- $\Delta o m p d c$ tachyzoites survived (Fig. 3a). These results indicated that the virulence of the RH- $\Delta o m p d c$ mutant was severely attenuated. The protective effects of the $\mathrm{RH}-\Delta o m p d c$ immunization on mice against its parental RH strain infection were further assessed. Mice were immunized (i.p.) with PBS or with $10^{6}$ or $2 \times 10^{6}$ RH- $\Delta o m p d c$ tachyzoites for 30 days and then challenged with $100 \mathrm{RH}-\mathrm{WT}$ tachyzoites. At the end of the 30-day observation period, the survival rate of the mice 

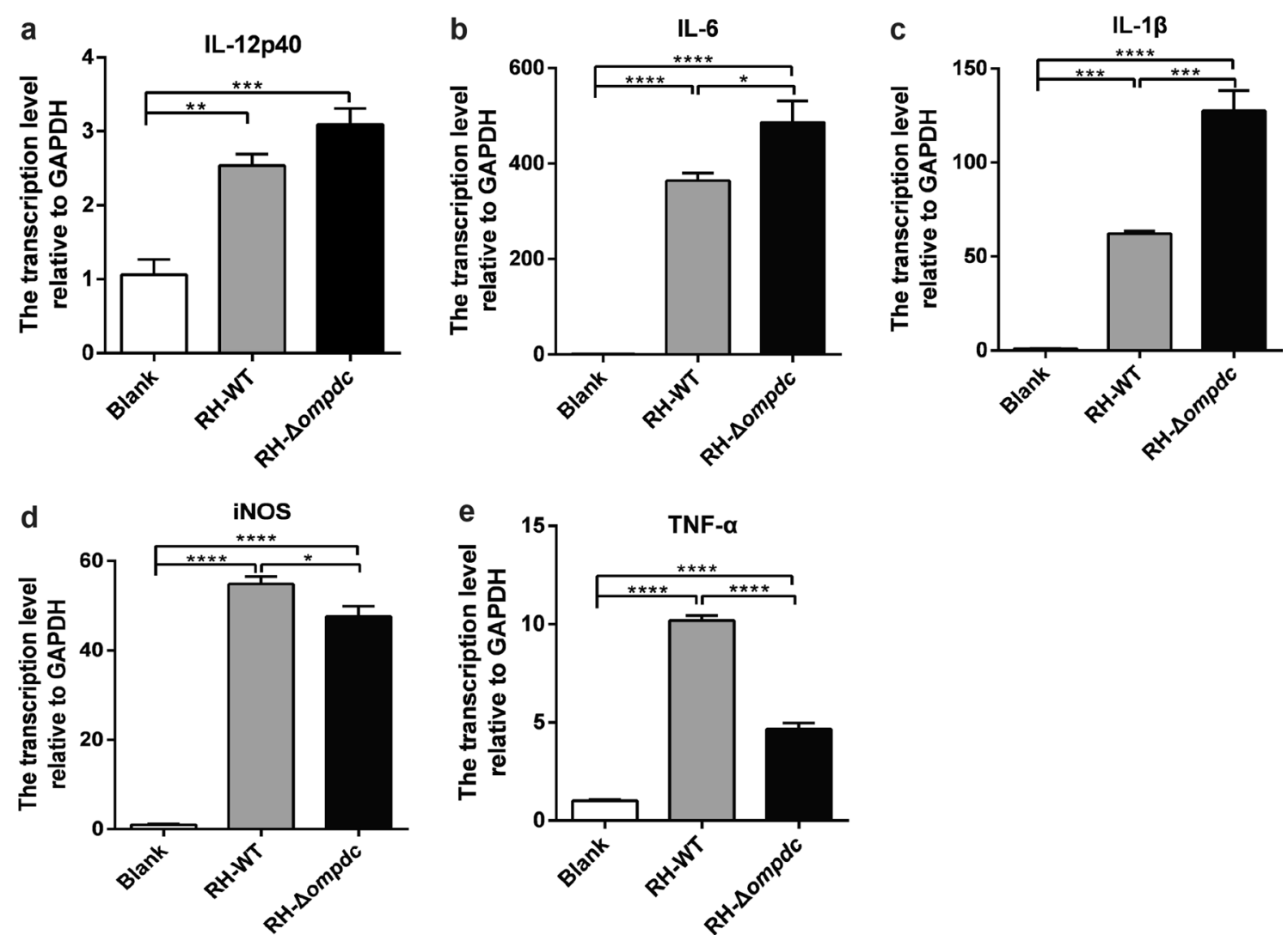

Fig. 2 Relative transcription levels of cytokines in RAW264.7 cells after RH-WT and RH- $\triangle$ ompdc infection. The relative transcription levels of IL-12p40 $(\mathbf{a})$, IL-6 (b), IL-1 $\beta$ (c), iNOS (d) and TNF-a (e) normalized with GAPDH were significantly increased in both RH-WT and RH- $\triangle$ ompdc infection groups compared to the control group. Results are representative of three independent experiments. Data were analyzed by one-way ANOVA with Tukey's test. Asterisks indicate significant difference at ${ }^{*} P<0.05,{ }^{* *} P<0.01$, ${ }^{* *} P<0.001$ and ${ }^{* * *} P<0.0001$.

vaccinated with $10^{6} \mathrm{RH}-\Delta o m p d c$ tachyzoites was $71.4 \%$ and that of the mice vaccinated with $2 \times 10^{6}$ tachyzoites was $100 \%$ (Fig. 3b). These results demonstrated that $\mathrm{RH}-\Delta o m p d c$ was avirulent in mice and that vaccination with this mutant could protect mice from reinfection by its parental virulent $\mathrm{RH}$ strain.

$\mathrm{RH}-\Delta$ ompdc could not propagate in mice but could induce intense immune responses during acute infection

The proliferative ability of $\mathrm{RH}-\Delta o m p d c$ in mice and the levels of the cytokines IL-12 and IFN- $\gamma$ in mice serum were further assessed. Mice were infected with $10^{6}$ tachyzoites of RH-WT and RH- $\Delta o m p d c$ by i.p. injection, and the parasite burden in the peritoneal fluids was subsequently examined by qPCR at $12 \mathrm{~h}, 24 \mathrm{~h}$ and 5 days after infection. At $24 \mathrm{~h}$ post infection, $\mathrm{RH}-\mathrm{WT}$ displayed robust replication and high parasite burden in the peritoneal fluids, while RH- $\Delta o m p d c$ showed a significant reduction in intraperitoneal parasites, and was eliminated within 5 days after infection (Fig. 4a). The mice sera were collected at different time points after infection for the detection of the Th1 cytokines IL-12 and IFN- $\gamma$. The levels of IL-12 and IFN- $\gamma$ in the serum were significantly upregulated after RH-WT and RH- $\Delta o m p d c$ infection (Fig. 4b, c). This result indicated that RH- $\Delta o m p d c$ induced strong host immune responses, similarly to its parental RH strain. However, in the RH- $\Delta o m p d c$ infection group, the levels of IL-12 and IFN- $\gamma$ first increased and then rapidly declined although they were still remarkably higher than those in the control group at 5 days past infection (Fig. $4 \mathrm{~b}, \mathrm{c}$ ). In brief, RH- $\Delta o m p d c$ could be rapidly cleared in mice but also induced a strong immune responses, as with its parental RH strain.

\section{The highly attenuated $T$. gondii strain RH- $\Delta$ ompdc inhibited 4T1 tumor growth}

The 4T1 breast carcinoma is derived from BALB/c mice and shows many common characteristics with the naturally occurring human TNBC. Therefore, this carcinoma is widely used as a tumor model to evaluate the therapeutic approaches for human mammary carcinoma. We 

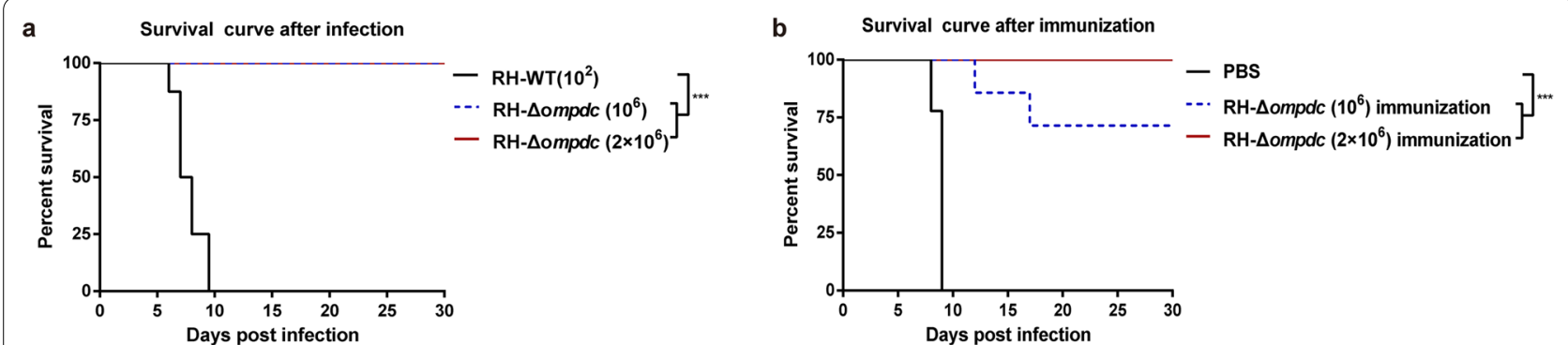

Fig. 3 Detection of the virulence and protective effects of the RH- $\triangle$ ompdc strain in mice. a Attenuated virulence of the RH- $\triangle$ ompdc strain in mice was observed. Mice $(n=8)$ infected with 100 RH-WT tachyzoites (i.p.) all died within 10 days, and mice $(n=8)$ infected with $10^{6}$ or $2 \times 10^{6}$ $\mathrm{RH}-\triangle o m p d c$ tachyzoites (i.p.) all survived. b RH- $\triangle$ ompdc immunization provided protection against RH-WT infection. After being immunized with PBS or $1 \times 10^{6}$ or $2 \times 10^{6} \mathrm{RH}-\triangle$ ompdc (i.p.) for 30 days, the mice were challenged with $100 \mathrm{RH}-$ WT tachyzoites (i.p.). The mice in the PBS group $(n=7)$ all died within 9 days after the challenge, while the mice in the $1 \times 10^{6}$ and $2 \times 10^{6} \mathrm{RH}-\triangle$ ompdc immunization groups $(n=7)$ showed survival rates of 71.4 and $100 \%$, respectively. Results are representative of three independent experiments. Data were analyzed by survival curves: log-rank (Mantel-Cox) test. Asterisks indicate significant difference at ${ }^{* * *} P<0.001$. Abbreviations: i.p., intraperitoneal injection; PBS, phosphate-buffered saline

assessed the efficacy of RH- $\Delta o m p d c$ for treating $4 \mathrm{~T} 1$ murine breast cancer. RH- $\Delta$ ompdc tachyzoites were inoculated i.t. at a dose of $10^{6}$ tachyzoites per injection. The treatments were administered every 7 days for a total of four times (Fig. 5a). The RH-Dompdc treatment was well-tolerated by mice, with no significant body weight loss in the treatment and control groups throughout the observation period (Fig. 5b). However, the RH- $\Delta o m p d c$ treatment remarkably inhibited tumor growth. The weight and volume of the tumors significantly decreased in the RH- $\Delta o m p d c$ treatment group compared to the PBS treatment group (Fig. 5c, d). At 20 days after the initial treatment, tumor volumes in the PBS treatment group were approximately threefold larger than those in the $\mathrm{RH}-\Delta o m p d c$ treatment group (Fig. $5 \mathrm{~d}$ ). The RH- $\Delta o m p d c$ treatment also significantly improved the survival of the tumor-bearing mice, with a median survival of 56 days, compared to only 36 days in the PBS treatment group (Fig. 5e). These results indicated that anti-tumor immune responses were induced after $\mathrm{RH}-\Delta o m p d c$ in situ inoculation into 4T1 tumors, leading to the inhibition of tumor growth and improved survival of the 4T1 tumor-bearing mice.
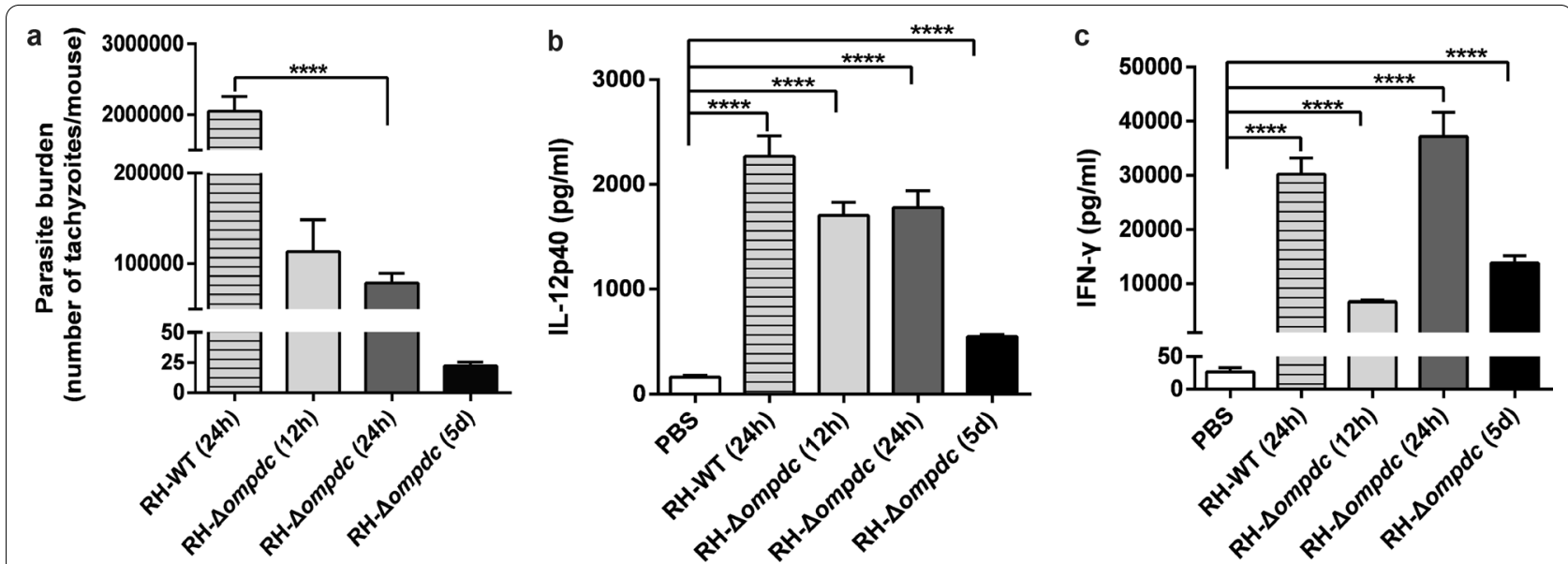

Fig. 4 The RH- $\triangle$ ompdc mutant could be eliminated in mice and induced intense host immune responses. The 6- to 8-week-old BALB/c mice were infected with $10^{6} \mathrm{RH}-\mathrm{WT}$ and $\mathrm{RH}-\triangle \mathrm{Ompdc}$ tachyzoites (i.p.), and the parasite burden in the peritoneal fluids and the levels of IL-12 and IFN- $\gamma$ in the serum were detected at $0,12,24 \mathrm{~h}$, and $5 \mathrm{~d}$ post infection. a The parasite burden in the peritoneal fluids of mice $(n=4)$ infected with RH-WT and $\mathrm{RH}-\triangle o m p d c$ tachyzoites was detected at the indicated time post infection. The B1 gene was detected by qPCR to demonstrate the number of T. gondii tachyzoites in each sample. $\mathbf{b} \mid \mathrm{L}-12$ level in mice serum $(n=5)$. $\mathbf{c} \mid \mathrm{FN}-\gamma$ level in mice serum $(n=4)$. Results are representative of three independent experiments. Data were analyzed by one-way ANOVA with Tukey's test. Asterisks indicate significant difference at ${ }^{* * * *} P<0.0001$ 


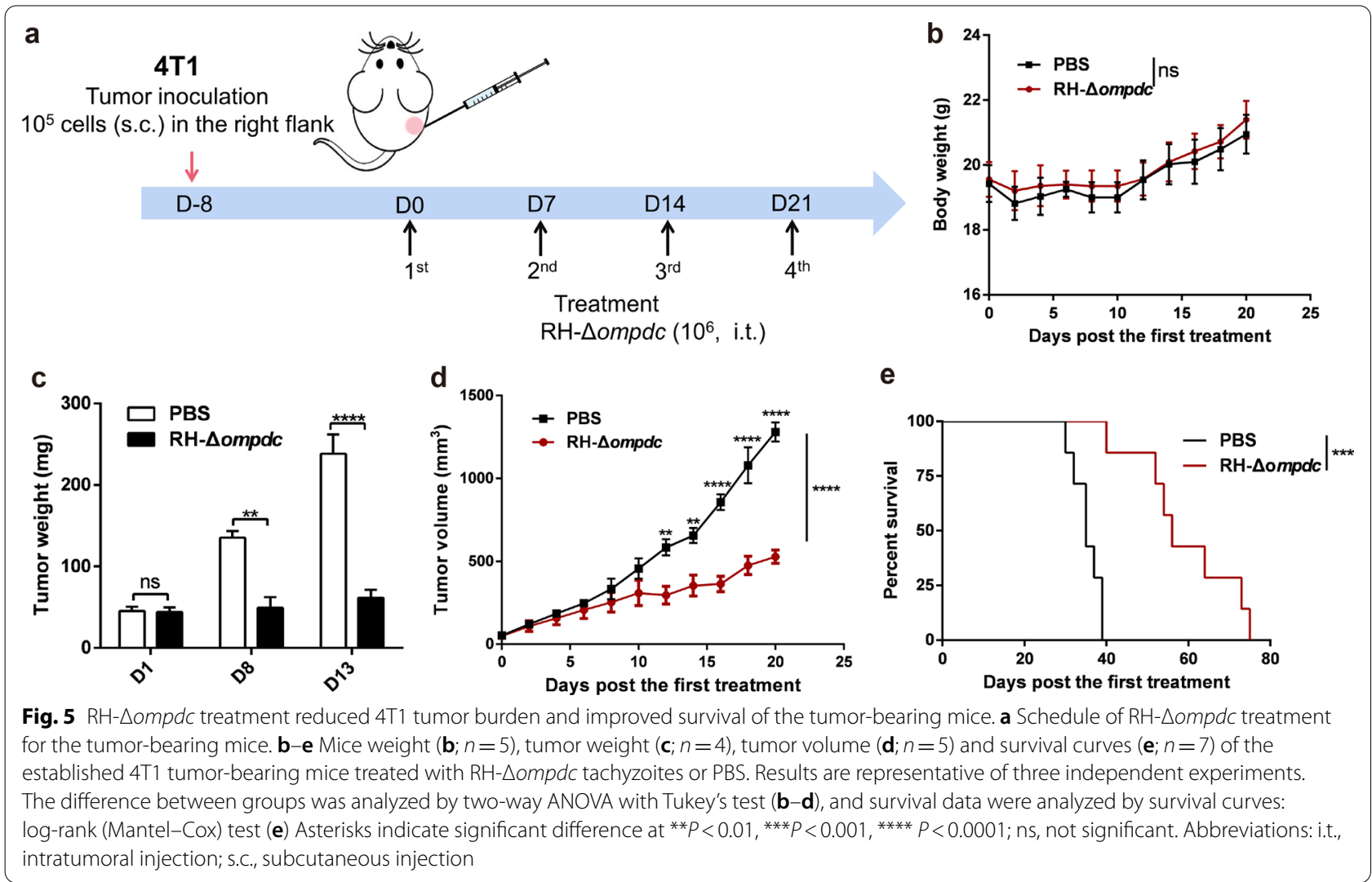

\section{$\mathrm{RH}-\Delta o m p d c$ treatment inhibited 4T1 cell lung metastasis}

4T1 metastatic disease spontaneously develops in the lungs of mice from the primary tumor as early as 8 days post inoculation, with increasing tumor burden at later time points [46]. In 4T1 tumor-bearing mice, lung metastasis is characterized by the infiltration of myeloid-derived suppressor cells and granulocytes [47]. The $\mathrm{RH}-\Delta o m p d c$ treatment of 4T1 tumors was carried out as described in the Methods section. The lungs of the mice were harvested on day 13 after the first treatment, stained with $H \& E$ and observed under a light microscope. Fewer infiltrating myeloid cells and larger alveoli spaces were found in the lung tissue of RH- $\Delta$ ompdc treatment group compared to that of the PBS group (Fig. 6a). The results indicated that extensive metastatic tumors had formed in the lungs of PBS-treated mice and that the lung architecture of RH- $\Delta o m p d c$-treated mice was similar to that of the healthy mice (Fig. 6a). The Ki67 protein, a nonhistone nuclear protein, is widely used as a proliferation marker for tumor cells. Due to the lack of specific markers for metastatic 4T1 tumor cells, we detected the 4T1 cells in lungs by immunohistochemical staining with the Ki67 antibody. The results showed that the number of Ki67-positive cells was significantly reduced in the RH- $\Delta o m p d c$ treatment group compared to the PBS group (Fig. 6b). The quantification of stained sections also showed a significant reduction in the number of Ki67-positive cells in the lung tissues of the RH- $\Delta o m p d c$ treatment group compared to the PBS group (Fig. 6c). In summary, the RH- $\Delta$ ompdc treatment was able to effectively inhibit the $4 \mathrm{~T} 1$ lung metastasis.

\section{$\mathrm{RH}-\Delta o m p d c$ treatment increased the IL-12 and IFN- $\gamma$ level in both the serum and tumor microenvironment (TME)} Cytokines, such as the proinflammatory cytokines IL-12 and IFN- $\gamma$, play crucial roles in inhibiting the progression of breast cancer, so cytokine analysis of the serum and TME may provide important clues about the immunomodulatory effects of RH- $\Delta o m p d c$ treatment. Following $\mathrm{RH}-\Delta o m p d c$ in situ inoculation to the $4 \mathrm{~T} 1$ tumor, we determined the cytokine levels by ELISA in serum and homogenized tumor lysate collected 1, 8, and 13 days after the first treatment. The levels of IL-12 and IFN- $\gamma$ in the $\mathrm{RH}-\Delta o m p d c$ treatment group were significantly upregulated in both the serum and TME, as compared to the PBS group (Fig. 7). However, the levels of IL-12 and IFN- $\gamma$ were decreased in both the serum and TME on day 13 after the first treatment (Fig. 7). Overall, the 


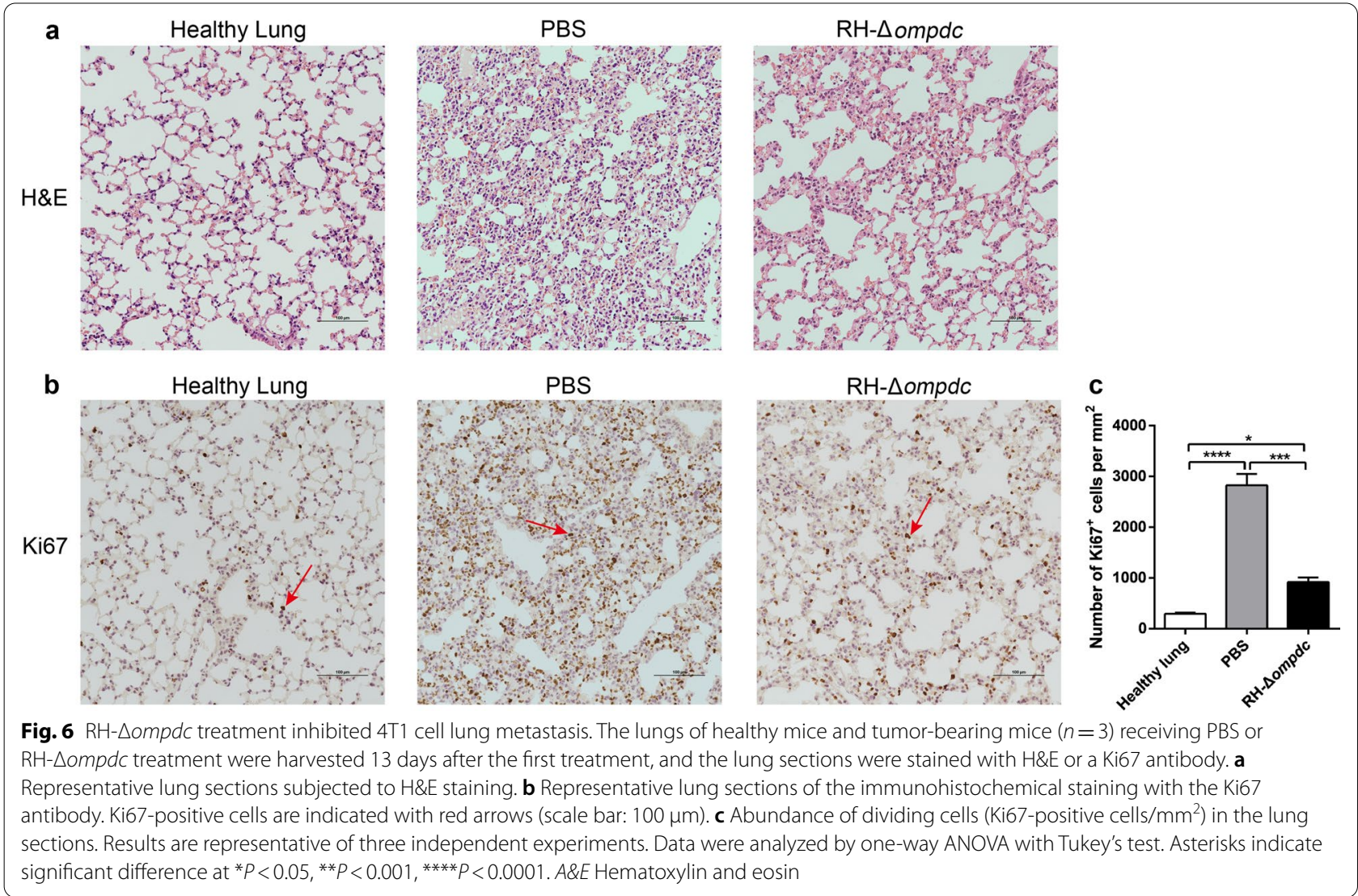

higher expression levels of IL-12 and IFN- $\gamma$ induced by the RH- $\Delta o m p d c$ treatment implied that this uracil auxotroph $T$. gondii may activate immune cells and induce anti-tumor immune responses.

\section{Discussion}

Toxoplasma gondii is frequently used as a model pathogen for the studies of Th1 cell-mediated immunity in intracellular infections. It has been reported that live avirulent parasites are more capable of inhibiting the growth of mice melanoma, ovarian, and pancreatic cancer than dead parasites, which suggests that the active invasion of the parasites is required for the induction of strong immune responses [34-36]. In our study, we constructed the uracil auxotroph $T$. gondii strain RH- $\Delta o m p d c$, and its virulence and the potential to be used in cancer biotherapy were evaluated. We found that RH- $\Delta o m p d c$ proliferation was blocked in the absence of uracil in vitro, which was consistent with reports by other researchers $[40,41]$. RH- $\Delta o m p d c$ tachyzoites could also be eliminated in mice, suggesting that they are avirulent and safe to the hosts (Fig. 8). During $T$. gondii infection, the early production of IL-12 is driven by inflammatory monocytes [48, 49]. It is mainly active $\mathrm{CD} 8 \alpha^{+}$dendritic cells (DCs) [50], rather than neutrophils, that contribute to the production of IL-12 [51]. IL-12 signaling is a major pathway that leads to the secretion of IFN- $\gamma$ by NK and T cells [52, 53], and IFN- $\gamma$ is the major mediator of resistance against $T$. gondii in hosts $[54,55]$. In our research, although proliferation was inhibited, RH- $\Delta o m p d c$ tachyzoites still maintained the ability to induce immune responses as its wild-type strain, which significantly increased the expression of proinflammatory cytokines such as IL-12 and IFN- $\gamma$. Nevertheless, the immune responses tended to return to normal as the infection continued. Five days after infection with $10^{6} \mathrm{RH}-\Delta o m p d c$ tachyzoites, the parasites in mice peritoneal fluids were almost eliminated, and the levels of IL-12 and IFN- $\gamma$ had accordingly decreased, which indicated that the effect of a one-time treatment to the $4 \mathrm{~T} 1$ tumor with $\mathrm{RH}-\Delta o m p d c$ may be not enough. Therefore, the tumor-bearing mice were treated every 7 days for a total of four times in our experiments. Cytokines and immune cells constitute a complex regulatory and effector network during disease processes; they are important components for host anti-infection and anti-tumor immunity $[8,56]$. We therefore focused on the expression of IL-12 and IFN- $\gamma$, 

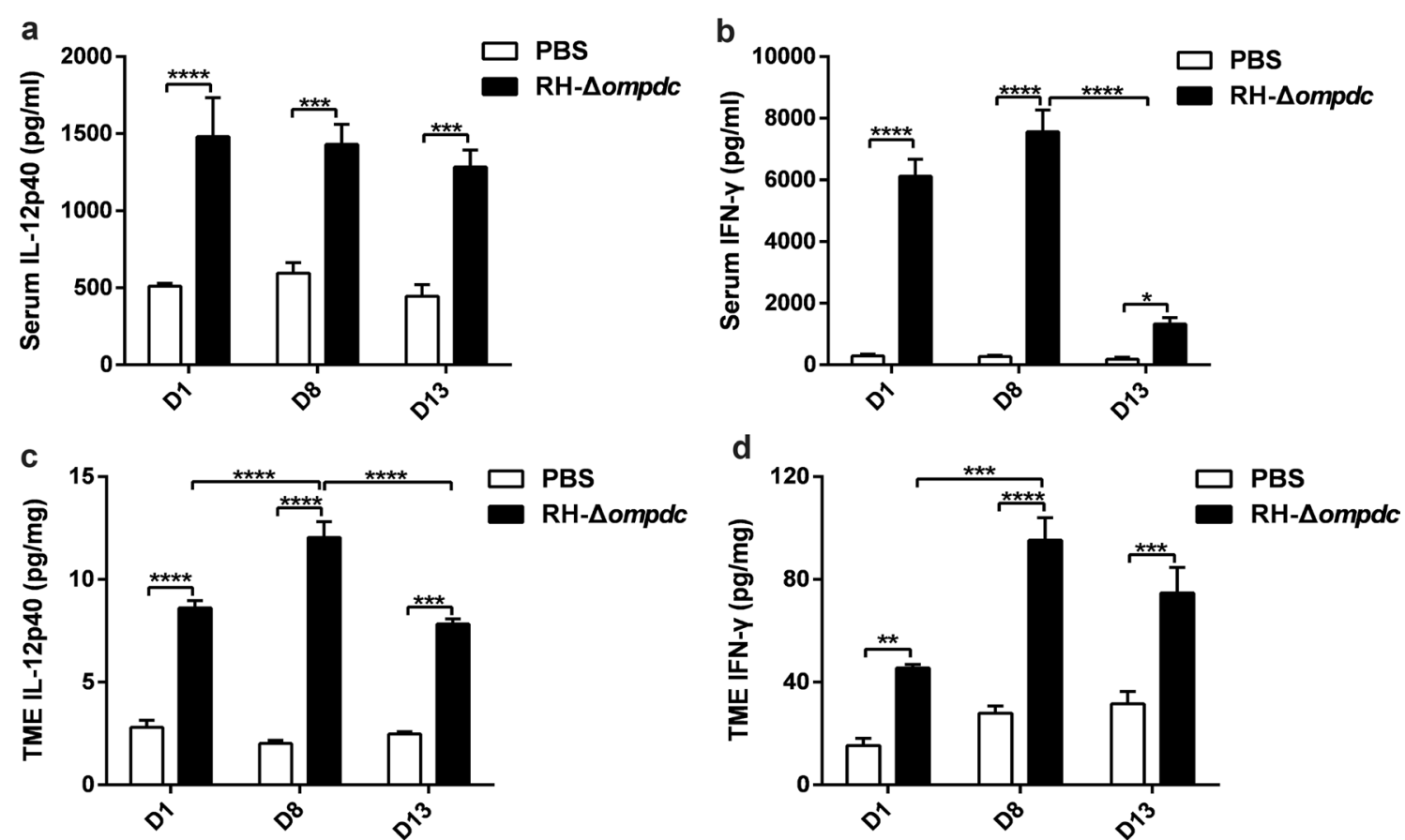

Fig. $7 \mathrm{RH}-\triangle$ ompdc treatment increased the levels of IL-12 and IFN- $\gamma$ in both the serum and TME. The 4T1 tumor-bearing mice model was established as illustrated in Fig. 5a, and the levels of the cytokines IL-12 and IFN- $\gamma$ in the serum and TME were determined by ELISA at 1, 8, and 13 days after the first treatment. $\mathbf{a}, \mathbf{b}$ Levels of IL-12 (a) and IFN- $\gamma(\mathbf{b})$ in the serum were detected $(n=4)$. c , $\mathbf{d}$ Levels of IL-12 (c) and IFN- $\gamma$ (d) in the TME were detected $(n=3)$. Results are representative of three independent experiments. Data were analyzed by two-way ANOVA with Tukey's test. Asterisks indicate significant difference at ${ }^{*} P<0.05,{ }^{* *} P<0.01$, ${ }^{* *} P<0.001$, and ${ }^{* * * *} P<0.0001$

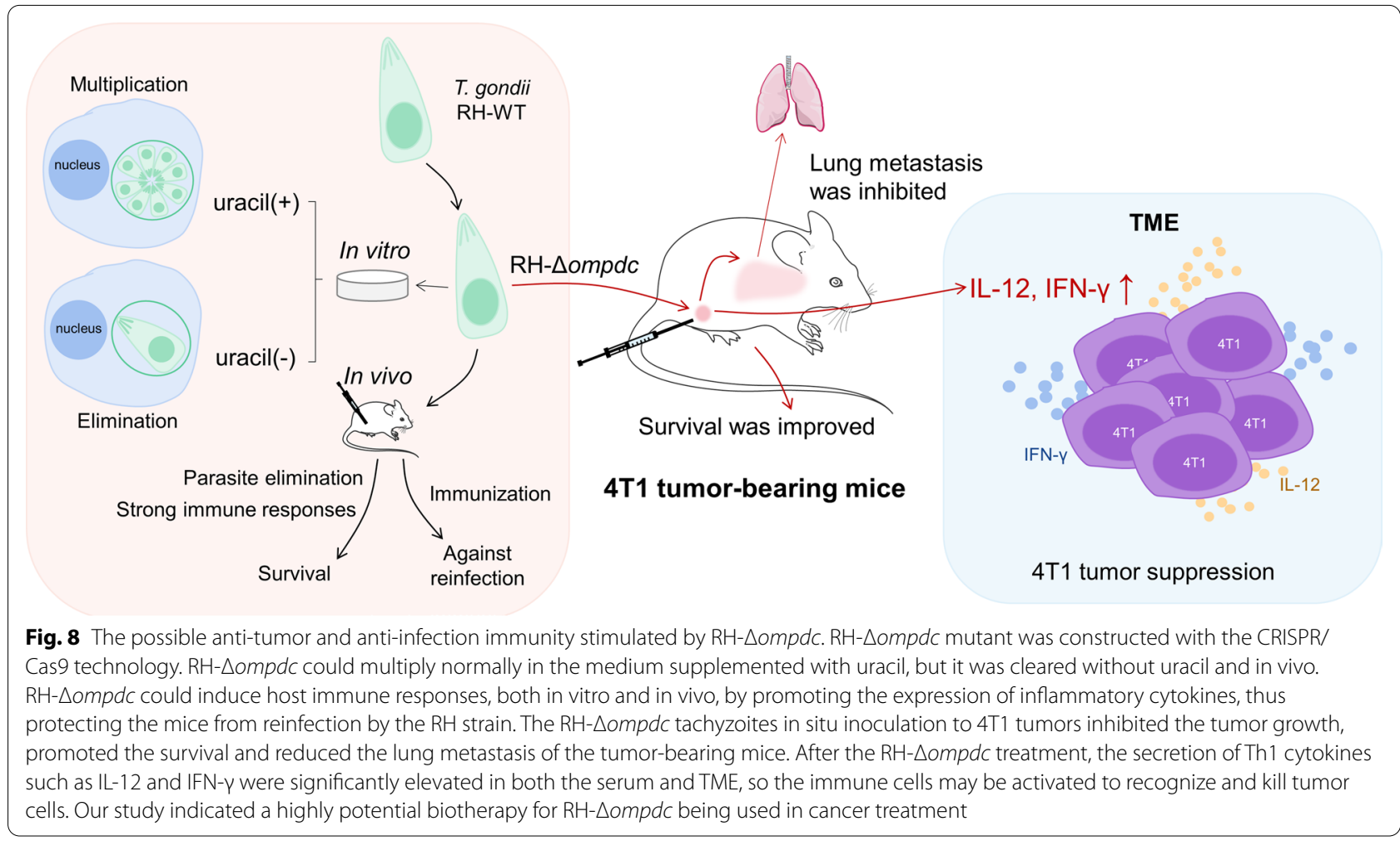


which are associated with breast cancer and positively influence anti-tumor immune responses.

As the most common aggressive breast cancer, TNBC remains difficult to control, despite a large number of therapeutic approaches having been evaluated. Nowadays, traditional treatments of breast cancer with surgery, radiation therapy and chemotherapy are the main therapeutic options in clinical practice $[2,5,6]$. However, chemotherapy and many of the novel immunotherapy strategies are associated with the development of complications. Therefore, it is urgent to search for other safe and effective therapeutic strategies targeting TNBC. The $T$. gondii uracil auxotroph $\Delta$ cps has shown strong antitumor activity in some tumor models, and the tumor growth inhibition of T. gondii treatment relies on $\mathrm{CD} 8^{+} \mathrm{T}$ cell activation [33-37]. Our results provide striking evidence of the distinct anti-tumor efficacy of RH- $\Delta$ ompdc in situ inoculation against 4T1 mouse breast tumors. $\mathrm{RH}-\Delta o m p d c$ treatment notably inhibited tumor growth, reduced lung metastasis and improved the survival of the tumor-bearing mice (Fig. 8). However, due to its resistance to pyrimethamine, the RH- $\Delta o m p d c$ strain can only be used for experimental biotherapy.

Cytokine profiling indicated that secretion of IL-12 and IFN- $\gamma$ significantly increased in the RH- $\Delta o m p d c$ treatment group in both the serum and TME of tumorbearing mice, suggesting vital roles for IL-12 and IFN- $\gamma$ (Fig. 8). IL-12 and IFN- $\gamma$ administration can inhibit the growth of $4 \mathrm{~T} 1$ tumors [57-60]. IL-12 is mainly secreted by activated antigen-presenting cells, and it links innate immune responses with adaptive immune responses [61]. Additionally, in tumor immunotherapy, IL-12 therapy induces Th1 cell differentiation [62], increases the infiltration of NK and $\mathrm{CD}^{+} \mathrm{T}$ cells to tumor sites [63] and triggers an anti-angiogenic program to exert anti-tumor activity $[64,65]$. Based on the higher detected levels of IL-12 and IFN- $\gamma$ in our study, $\mathrm{RH}-\Delta o m p d c$ treatment may enhance anti-tumor immune responses. In the progression of anti-tumor immunity, NK cells, Th1 cells, and cytotoxic T lymphocytes (CTLs) are the main effector cells. IFN- $\gamma$ is mainly secreted by NK and NKT cells in innate immunity and by Th1 or CTL cells in adaptive immunity [66]. IFN- $\gamma$ plays a key role in the activation of cellular immunity and anti-tumor immune responses. IFN- $\gamma$ signaling directly activates apoptotic processes and induces the apoptosis of cancer cells [67]. IFN- $\gamma$ also inhibits angiogenesis in tumor tissue [68] and stimulates the activity of M1 macrophages to inhibit tumor progression [69]. The presence of these cytokines and immune cells in the TME has been shown to be associated with a good prognosis for many types of solid tumors, and abundant immunosuppressive cells, such as Tregs, MDSCs and TAMs, can achieve immune evasion and the tolerance of tumors [70, 71]. It is worth noting that Tregs are FoxP3 ${ }^{+} \mathrm{CD}^{+} \mathrm{T}$ cells that regulate immune tolerance and suppress dendritic cell (DC) maturation and $\mathrm{CD}^{+} \mathrm{T}$ cell recruitment to the TME [72]. MDSCs play an important role in inhibiting the activation of $\mathrm{T}$ cells, NK cells, and other immune cells [73]. TAMs usually display an anti-inflammatory M2-like phenotype and are frequently associated with tumor growth and metastasis [74]; they also suppress $\mathrm{CD}^{+} \mathrm{T}$ cell recruitment to the TME [75].

$\mathrm{RH}-\Delta o m p d c$ treatment increased the expression of IL-12 and IFN- $\gamma$, which may inhibit tumor angiogenesis, activate APCs and induce infiltrating $\mathrm{T}$ cells in the TME, thus reversing tumor immunosuppression to suppress $4 \mathrm{~T} 1$ breast tumor growth and lung metastasis, and even induce systemic anti-tumor immunity. Further research is needed to reveal the anti-tumor mechanisms driven by IL-12 and IFN- $\gamma$ in the $4 \mathrm{~T} 1$ tumor model, and the activated $\mathrm{DCs}, \mathrm{NK}, \mathrm{CD}^{+}$and $\mathrm{CD} 8^{+} \mathrm{T}$ cells, as well as immunosuppressive cells in the TME. Furthermore, combination strategies may magnify antitumor immune responses and therapeutic effects [76, 77]. Therapies combining RH- $\Delta o m p d c$ with other antitumor agents may achieve better therapeutic effects. $\mathrm{RH}-\Delta o m p d c$ may be a highly potential vaccine for treating malignancies, and the underlying anti-tumor mechanism is worth investigating.

\section{Conclusions}

In summary, our study demonstrated that the $\mathrm{RH}-\Delta o m p d c$ mutant can grow normally in vitro with uracil supplement, but is unable to propagate without uracil addition and in vivo. Therefore, it is avirulent to the hosts. Inoculation of RH- $\Delta o m p d c$ in situ resulted in anti-tumor efficacy against 4T1 tumor growth and lung metastasis. The RH- $\Delta o m p d c$ infection increased the secretion of the Th1 cytokines IL-12 and IFN- $\gamma$, which may activate immune cells to recognize and kill tumor cells. However, mechanistic experiments still need to be performed to determine the anti-tumor mechanisms that are driven by IL12 and IFN- $\gamma$ in the $4 \mathrm{~T} 1$ tumor model. Our study indicates that RH- $\Delta$ ompdc therapy has high potential as a biotherapy for the treatment of breast cancer.

\section{Abbreviations}

ELISA: Enzyme-linked immunosorbent assay; GAPDH: Glyceraldehyde 3-phosphate dehydrogenase; HFF: Human foreskin fibroblast; IFN: Interferon; IL: Interleukin; iNOS: Inducible nitric oxide synthase; OMPDC: Orotidine 
5'-monophosphate decarboxylase; QRT-PCR: Quantitative reverse transcription PCR; TME: Tumor microenvironment; TNBC: Triple-negative breast cancer; TNFa: Tumor necrosis factor-a.

\section{Supplementary Information}

The online version contains supplementary material available at https://doi. org/10.1186/s13071-021-05032-6.

Additional file 1: Figure S1. The primers used for construction and identification of the $\mathrm{RH}-\Delta_{\text {ompdc }}$ mutant.

Additional file 2: Table S1. The primers used for qRT-PCR.

\section{Acknowledgements}

The authors are grateful to the participants in this study and the anonymous reviewers and editors for their comments and valuable inputs.

\section{Authors' contributions}

HJP and LQX designed the study. LQX, LJY, DJ, LJZ, MC and WHZ performed the experiments. LQX, LJY, DJ and WZL collected and statistically analyzed the data. LQX made major contributions to the writing of the manuscript. HJP conducted the project administration, supplied resources, supervised the research, and validated the manuscript. All authors read and approved the final manuscript.

\section{Funding}

This research was supported by National Natural Science Foundation of China (81971954), Science and Technology Planning Project of Guangdong Province (2018A050506038), Key project of Guangzhou science research (201904020011), and the Basic Research Project of Key Laboratory of Guangzhou (202102100001) to HJP.

\section{Availability of data and materials}

The datasets supporting the findings of this article are included within the article.

\section{Declarations}

\section{Ethics approval and consent to participate}

All animal experimental procedures were approved by the Experimental Animal Care and Use Committee of Southern Medical University (Permit No. L2019155) and performed strictly according to the guidelines for animal care in Southern Medical University.

\section{Consent for publication}

Not applicable.

\section{Competing interests}

The authors declare that they have no competing interests.

Received: 26 February 2021 Accepted: 23 September 2021

Published online: 11 December 2021

\section{References}

1. Ferlay J, Colombet M, Soerjomataram I, Mathers C, Parkin DM, Pineros $M$, et al. Estimating the global cancer incidence and mortality in 2018: GLOBOCAN sources and methods. Int J Cancer. 2019;144:1941-53.

2. Harbeck N, Penault-Llorca F, Cortes J, Gnant M, Houssami N, Poortmans P, et al. Breast cancer. Nat Rev Dis Primers. 2019;5:66.

3. Vagia E, Mahalingam D, Cristofanilli M. The landscape of targeted therapies in TNBC. Cancers (Basel). 2020;12:916.

4. Dent R, Trudeau M, Pritchard Kl, Hanna WM, Kahn HK, Sawka CA, et al. Triple-negative breast cancer: clinical features and patterns of recurrence. Clin Cancer Res. 2007;13:4429-34.

5. Waks AG, Winer EP. Breast cancer treatment: a review. JAMA. 2019;321:288-300.
6. Gradishar WJ, Anderson BO, Balassanian R, Blair SL, Burstein HJ, Cyr A, et al. Invasive breast cancer version 1.2016, NCCN clinical practice guidelines in oncology. J Natl Compr Canc Netw. 2016;14:324-54.

7. Denkert C, Liedtke C, Tutt A, von Minckwitz G. Molecular alterations in triple-negative breast cancer-the road to new treatment strategies. Lancet. 2017;389:2430-42.

8. Hinshaw DC, Shevde LA. The tumor microenvironment innately modulates cancer progression. Cancer Res. 2019;79:4557-66.

9. Mellman I, Coukos G, Dranoff G. Cancer immunotherapy comes of age. Nature. 2011:480:480-9.

10. Vanneman M, Dranoff G. Combining immunotherapy and targeted therapies in cancer treatment. Nat Rev Cancer. 2012;12:237-51.

11. Stein T, Salomonis N, Nuyten DS, van de Vijver MJ, Gusterson BA. A mouse mammary gland involution mRNA signature identifies biological pathways potentially associated with breast cancer metastasis. J Mammary Gland Biol Neoplasia. 2009;14:99-116.

12. Clarkson RW, Wayland MT, Lee J, Freeman T, Watson CJ. Gene expression profiling of mammary gland development reveals putative roles for death receptors and immune mediators in post-lactational regression. Breast Cancer Res. 2004;6:R92-109.

13. Stein T, Morris JS, Davies CR, Weber-Hall SJ, Duffy MA, Heath VJ, et al. Involution of the mouse mammary gland is associated with an immune cascade and an acute-phase response, involving LBP, CD14 and STAT3. Breast Cancer Res. 2004;6:R75-91.

14. Boudreau A, van't Veer LJ, Bissell MJ. An "elite hacker": breast tumors exploit the normal microenvironment program to instruct their progression and biological diversity. Cell Adh Migr. 2012;6:236-48.

15. Schreiber RD, Old LJ, Smyth MJ. Cancer immunoediting: integrating immunity's roles in cancer suppression and promotion. Science. 2011;331:1565-70.

16. Smyth MJ, Dunn GP, Schreiber RD. Cancer immunosurveillance and immunoediting: the roles of immunity in suppressing tumor development and shaping tumor immunogenicity. Adv Immunol. 2006;90:1-50.

17. Nanda R, Chow LQ, Dees EC, Berger R, Gupta S, Geva R, et al. Pembrolizumab in patients with advanced triple-negative breast cancer: phase Ib KEYNOTE-012 study. J Clin Oncol. 2016;34:2460-7.

18. Lyon AR, Yousaf N, Battisti NML, Moslehi J, Larkin J. Immune checkpoint inhibitors and cardiovascular toxicity. Lancet Oncol. 2018;19:e447-58.

19. Zhou S, Gravekamp C, Bermudes D, Liu K. Tumour-targeting bacteria engineered to fight cancer. Nat Rev Cancer. 2018;18:727-43.

20. Ni D, Qing S, Ding H, Yue H, Yu D, Wang S, et al. Biomimetically engineered demi-bacteria potentiate vaccination against cancer. Adv Sci (Weinh). 2017:4:1700083.

21. Chowdhury S, Castro S, Coker C, Hinchliffe TE, Arpaia N, Danino T. Programmable bacteria induce durable tumor regression and systemic antitumor immunity. Nat Med. 2019;25:1057-63.

22. Deng W, Lira V, Hudson TE, Lemmens EE, Hanson WG, Flores R, et al. Recombinant Listeria promotes tumor rejection by CD8(+) T celldependent remodeling of the tumor microenvironment. Proc Natl Acad Sci USA. 2018:115:8179-84

23. Zheng DW, Chen Y, Li ZH, Xu L, Li CX, Li B, et al. Optically-controlled bacterial metabolite for cancer therapy. Nat Commun. 2018;9:1680.

24. Xu W, Zhou T, Zhou J, Qiang Z, Zhang J, Hua Z. Attenuated Salmonella VNP20009 mutant (DeltahtrA) is a promising candidate for bacteriamediated tumour therapy in hosts with TNFR1 deficiency. Lett Appl Microbiol. 2018;67:97-103.

25. Lizotte PH, Baird JR, Stevens CA, Lauer P, Green WR, Brockstedt DG, et al. Attenuated Listeria monocytogenes reprograms M2-polarized tumorassociated macrophages in ovarian cancer leading to iNOS-mediated tumor cell lysis. Oncoimmunology. 2014;3:e28926.

26. Andtbacka RH, Kaufman HL, Collichio F, Amatruda T, Senzer N, Chesney $J$, et al. Talimogene laherparepvec improves durable response rate in patients with advanced melanoma. J Clin Oncol. 2015;33:2780-8.

27. Lizotte PH, Wen AM, Sheen MR, Fields J, Rojanasopondist P, Steinmetz $N F$, et al. In situ vaccination with cowpea mosaic virus nanoparticles suppresses metastatic cancer. Nat Nanotechnol. 2016;11:295-303. 
28. Czapar AE, Tiu BDB, Veliz FA, Pokorski JK, Steinmetz NF. Slow-release formulation of cowpea mosaic virus for in situ vaccine delivery to treat ovarian cancer. Adv Sci (Weinh). 2018;5:1700991.

29. Cai H, Wang C, Shukla S, Steinmetz NF. Cowpea mosaic virus immunotherapy combined with cyclophosphamide reduces breast cancer tumor burden and inhibits lung metastasis. Adv Sci (Weinh). 2019;6:1802281.

30. Shukla S, Wang C, Beiss V, Cai H, Washington T 2nd, Murray AA, et al. The unique potency of Cowpea mosaic virus (CPMV) in situ cancer vaccine. Biomater Sci. 2020;8:5489-503.

31. Aznar MA, Molina C, Teijeira A, Rodriguez I, Azpilikueta A, Garasa S, et al. Repurposing the yellow fever vaccine for intratumoral immunotherapy. EMBO Mol Med. 2019;12:e10375.

32. Fox BA, Sanders KL, Chen S, Bzik DJ. Targeting tumors with nonreplicating Toxoplasma gondii uracil auxotroph vaccines. Trends Parasitol. 2013;29:431-7.

33. Kim JO, Jung SS, Kim SY, Kim TY, Shin DW, Lee JH, et al. Inhibition of Lewis lung carcinoma growth by Toxoplasma gondii through induction of Th1 immune responses and inhibition of angiogenesis. J Korean Med Sci. 2007;22(Suppl):S38-46.

34. Baird JR, Byrne KT, Lizotte PH, Toraya-Brown S, Scarlett UK, Alexander MP, et al. Immune-mediated regression of established B16F10 melanoma by intratumoral injection of attenuated Toxoplasma gondii protects against rechallenge. J Immunol. 2013;190:469-78.

35. Baird JR, Fox BA, Sanders KL, Lizotte PH, Cubillos-Ruiz JR, Scarlett UK, et al. Avirulent Toxoplasma gondii generates therapeutic antitumor immunity by reversing immunosuppression in the ovarian cancer microenvironment. Cancer Res. 2013;73:3842-51.

36. Sanders KL, Fox BA, Bzik DJ. Attenuated Toxoplasma gondii stimulates immunity to pancreatic cancer by manipulation of myeloid cell populations. Cancer Immunol Res. 2015;3:891-901.

37. Sanders KL, Fox BA, Bzik DJ. Attenuated Toxoplasma gondii therapy of disseminated pancreatic cancer generates long-lasting immunity to pancreatic cancer. Oncoimmunology. 2016;5:e1104447.

38. Yarovinsky F. Innate immunity to Toxoplasma gondii infection. Nat Rev Immunol. 2014:14:109-21.

39. Lu G, Zhou J, Zhao YH, Li QL, Gao YY, Wang L. Transcriptome sequencing investigated the tumor-related factors changes after T. gondii infection. Front Microbiol. 2019;10:181.

40. Fox BA, Bzik DJ. De novo pyrimidine biosynthesis is required for virulence of Toxoplasma gondii. Nature. 2002;415:926-9.

41. Fox BA, Bzik DJ. Avirulent uracil auxotrophs based on disruption of orotidine-5'-monophosphate decarboxylase elicit protective immunity to Toxoplasma gondii. Infect Immun. 2010;78:3744-52.

42. Shen B, Brown K, Long S, Sibley LD. Development of CRISPR/Cas9 for efficient genome editing in Toxoplasma gondii. Methods Mol Biol. 2017;1498:79-103.

43. Shen B, Sibley LD. Toxoplasma aldolase is required for metabolism but dispensable for host-cell invasion. Proc Natl Acad Sci USA. 2014;111:3567-72.

44. Xia N, Yang J, Ye S, Zhang L, Zhou Y, Zhao J, et al. Functional analysis of Toxoplasma lactate dehydrogenases suggests critical roles of lactate fermentation for parasite growth in vivo. Cell Microbiol. 2018;20(1). https:// doi.org/10.1111/cmi.12794.

45. Li Y, Poppoe F, Chen J, Yu L, Deng F, Luo Q, et al. Macrophages polarized by expression of ToxoGRA15II inhibit growth of hepatic carcinoma. Front Immunol. 2017;8:137.

46. Kershaw MH, Jackson JT, Haynes NM, Teng MW, Moeller M, Hayakawa Y, et al. Gene-engineered T cells as a superior adjuvant therapy for metastatic cancer. J Immunol. 2004;173:2143-50.

47. DuPre SA, Redelman D, Hunter KW Jr. The mouse mammary carcinoma 4T1: characterization of the cellular landscape of primary tumours and metastatic tumour foci. Int J Exp Pathol. 2007;88:351-60.

48. Dunay IR, Damatta RA, Fusx B, Presti R, Greco S, Colonna M, et al. Gr1(+) inflammatory monocytes are required for mucosal resistance to the pathogen Toxoplasma gondii. Immunity. 2008;29:306-17.

49. Robben PM, LaRegina M, Kuziel WA, Sibley LD. Recruitment of $\mathrm{Gr}_{-1}{ }^{+}$ monocytes is essential for control of acute toxoplasmosis. J Exp Med. 2005;201:1761-9.
50. Mashayekhi M, Sandau MM, Dunay IR, Frickel EM, Khan A, Goldszmid RS, et al. CD8a(+) dendritic cells are the critical source of interleukin-12 that controls acute infection by Toxoplasma gondii tachyzoites. Immunity. 2011;35:249-59.

51. Dunay IR, Fuchs A, Sibley LD. Inflammatory monocytes but not neutrophils are necessary to control infection with Toxoplasma gondii in mice. Infect Immun. 2010;78:1564-70.

52. Gazzinelli RT, Hieny S, Wynn TA, Wolf S, Sher A. Interleukin 12 is required for the T-lymphocyte-independent induction of interferon gamma by an intracellular parasite and induces resistance in T-cell-deficient hosts. Proc Natl Acad Sci USA. 1993;90:6115-9.

53. Wilson DC, Matthews S, Yap GS. IL-12 signaling drives CD8 $8^{+}$T cell IFNgamma production and differentiation of $\mathrm{KLRG}^{+}$effector subpopulations during Toxoplasma gondii infection. J Immunol. 2008;180:5935-45.

54. Suzuki Y, Orellana MA, Schreiber RD, Remington JS. Interferon-gamma: the major mediator of resistance against Toxoplasma gondii. Science. 1988;240:516-8.

55. Dupont CD, Christian DA, Hunter CA. Immune response and immunopathology during toxoplasmosis. Semin Immunopathol. 2012;34:793-813.

56. Sasai $M$, Yamamoto M. Innate, adaptive, and cell-autonomous immunity against Toxoplasma gondii infection. Exp Mol Med. 2019;51:1-10.

57. Hu Q, Shang L, Wang M, Tu K, Hu M, Yu Y, et al. Co-Delivery of paclitaxel and interleukin-12 regulating tumor microenvironment for cancer immunochemotherapy. Adv Healthc Mater. 2020:9:e1901858.

58. Zhu S, Lee DA, Li S. IL-12 and IL-27 sequential gene therapy via intramuscular electroporation delivery for eliminating distal aggressive tumors. J Immunol. 2010;184:2348-54.

59. Gao H, Wu Y, Shi J, Zhang X, Liu T, Hu B, et al. Nuclear imaging-guided PD-L1 blockade therapy increases effectiveness of cancer immunotherapy. J Immunother Cancer. 2020;8:e001156.

60. Wu Y, Liu J, Movahedi F, Gu W, Xu T, Xu ZP. Enhanced prevention of breast tumor metastasis by nanoparticle-delivered vitamin e in combination with interferon-gamma. Adv Healthc Mater. 2020;9:e1901706.

61. Watford WT, Moriguchi M, Morinobu A, O'Shea JJ. The biology of IL-12: coordinating innate and adaptive immune responses. Cytokine Growth Factor Rev. 2003;14:361-8.

62. Wesa A, Kalinski P, Kirkwood JM, Tatsumi T, Storkus WJ. Polarized type-1 dendritic cells (DC1) producing high levels of IL-12 family members rescue patient $\mathrm{TH} 1$-type antimelanoma $\mathrm{CD}^{+} \mathrm{T}$ cell responses in vitro. J Immunother. 2007;30:75-82.

63. Trinchieri $\mathrm{G}$. Interleukin-12 and the regulation of innate resistance and adaptive immunity. Nat Rev Immunol. 2003;3:133-46.

64. Airoldi I, Di Carlo E, Cocco C, Taverniti G, D’Antuono T, Ognio E, et al. Endogenous IL-12 triggers an antiangiogenic program in melanoma cells. Proc Natl Acad Sci USA. 2007;104:3996-4001.

65. Lasek W, Zagozdzon R, Jakobisiak M. Interleukin 12: still a promising candidate for tumor immunotherapy? Cancer Immunol Immunother. 2014;63:419-35.

66. Burke JD, Young HA. IFN-gamma: A cytokine at the right time, is in the right place. Semin Immunol. 2019;43:101280.

67. Jorgovanovic D, Song M, Wang L, Zhang Y. Roles of IFN-gamma in tumor progression and regression: a review. Biomark Res. 2020;8:49.

68. George J, Banik NL, Ray SK. Combination of hTERT knockdown and IFN-gamma treatment inhibited angiogenesis and tumor progression in glioblastoma. Clin Cancer Res. 2009;15:7186-95.

69. Muller E, Christopoulos PF, Halder S, Lunde A, Beraki K, Speth M, et al. Toll-like receptor ligands and interferon-gamma synergize for induction of antitumor M1 macrophages. Front Immunol. 2017:8:1383.

70. Bruni D, Angell HK, Galon J. The immune contexture and Immunoscore in cancer prognosis and therapeutic efficacy. Nat Rev Cancer. 2020;20:662-80.

71. Law AMK, Lim E, Ormandy CJ, Gallego-Ortega D. The innate and adaptive infiltrating immune systems as targets for breast cancer immunotherapy. Endocr Relat Cancer. 2017;24:R123-44.

72. Facciabene A, Motz GT, Coukos G. T-regulatory cells: key players in tumor immune escape and angiogenesis. Cancer Res. 2012;72:2162-71.

73. Yang Y, Li C, Liu T, Dai X, Bazhin AV. Myeloid-derived suppressor cells in tumors: from mechanisms to antigen specificity and microenvironmental regulation. Front Immunol. 2020;11:1371. 
74. Wei C, Yang C, Wang S, Shi D, Zhang C, Lin X, et al. Crosstalk between cancer cells and tumor associated macrophages is required for mesenchymal circulating tumor cell-mediated colorectal cancer metastasis. Mol Cancer. 2019;18:64.

75. Petty AJ, Li A, Wang X, Dai R, Heyman B, Hsu D, et al. Hedgehog signaling promotes tumor-associated macrophage polarization to suppress intratumoral CD8 ${ }^{+}$T cell recruitment. J Clin Invest. 2019;129:5151-62.

76. Duan X, Chan C, Guo N, Han W, Weichselbaum RR, Lin W. Photodynamic therapy mediated by nontoxic core-shell nanoparticles synergizes with immune checkpoint blockade to elicit antitumor immunity and antimetastatic effect on breast cancer. J Am Chem Soc. 2016;138:16686-95.

77. Gotwals P, Cameron S, Cipolletta D, Cremasco V, Crystal A, Hewes B, et al. Prospects for combining targeted and conventional cancer therapy with immunotherapy. Nat Rev Cancer. 2017;17:286-301.

\section{Publisher's Note}

Springer Nature remains neutral with regard to jurisdictional claims in published maps and institutional affiliations.

- fast, convenient online submission

- thorough peer review by experienced researchers in your field

- rapid publication on acceptance

- support for research data, including large and complex data types

- gold Open Access which fosters wider collaboration and increased citations

- maximum visibility for your research: over $100 \mathrm{M}$ website views per year

At BMC, research is always in progress.

Learn more biomedcentral.com/submissions 